\title{
ГЛОБАЛЬНЫЕ МОДЕЛИ ГРАНИЦЫ МОХО
}

\author{
М.С. Чадаев \\ Горный институт УрО РАН, г. Пермь
}

\begin{abstract}
Аннотация: Проанализированы глобальные модели построения границы Мохоровичича (Мохо), созданные объединёнными учёными Западной Европы, а также в Америке, Италии и других странах. Величина сечения таких карт порядка 5 км. В основу положены данные сейсмических методов, а также гравиразведки и других методов.

Наиболее полно идея коплексирования методов воплощена итальянскими специалистами в глобальной модели построения границы Мохо, основыванной на комбинации сейсмической модели и карты второй радиальной производной гравитационного потенциала, полученной по спутниковой съёмке. Приведены фрагменты картопостроений, в том числе по системе ВЕКТОР, разработанной в Горном институте РПН.

Ключевые слова: граница Мохо, сейсморазведка, гравиразведка, модели карт.
\end{abstract}

Петрофизическая и геологическая граница Мохо, разделяющая земную кору и верхнюю мантию Земли - важный объект научных исследований в геологии.

Для картирования границы главенствующее значение имеет метод глубинного сейсмического зондирования (ГСЗ). При этом, как правило, учитываются данные гравиметрии, чему в большой мере способствует наличие банков гравиметрических данных.

Наибольшую толщину земная кора имеет в горах, а наименьшую - в океанах. Структурные карты и схемы поверхности Мохо позволяют выявить крупные тектонические элементы и оценить их связь с вышезалегающими неоднородностями, а также выявить закономерности размещения полезных ископаемых, практическими индикаторами которых зачастую служат глубинные разломы и морфология границы. В том числе для континентальной коры Арктики важно установить размещение мантийных рудных месторождений в зонах тектономагматической активизации и глубинных разломов, рифтогенных структурах и вулканических поясах. Локализация месторождений мантийного класса расширяет область поисков рудных месторождений (Д.А. Додин).

Составлен ряд современных глобальных карт [6]: European Moxo (2009) (28 N - 86 N, 40 W - 70 E); Australian Moxo (2011) (10 S - 45 S - 110 E - 160 E); North America Moxo (2009) (30 N - 50N, $70 \mathrm{~W}-100 \mathrm{~W})$; Jtaly Мохо (2010) - комбинация двух моделей CRUST2.0 model and GOCE data.

Разработанная итальянскими специалистами глобальная модель построения границы Мохо основывается на комбинации известной сейсмической модели CRUST2.0 и карты второй радиальной производной гравитационного потенциала, полученной по спутниковой съёмке $[6,9]$.

Вводя поправки в измеренные значения за толщу льда с плотностью 0,98 г/см ${ }^{3}$,

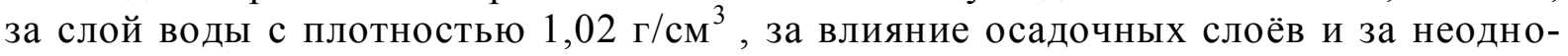
родности земной коры и верхней мантии, получено интегральное уравнение второй производной первого рода. Для его решения применён известный приём линеризации ядра уравнения [2]. В итоге была построена карта второй радиальной производной.

\section{Взаимосвязь аномалий силы тяжести}

\section{и глубины нахождения границы Мохо}

Основанием комплексирования служит наличие связи между изменениями петрофизическими свойствами и аномалиями силы тяжести. 
На рис. 1 приведена зависимость величины аномалий (плотность 2,67 г/см ${ }^{3}$ при осреднении в радиусе 100 м) от глубины границы Мохо для Циркумполярной области и Евразии [1].

Из диаграммы также следует существование достаточно тесной корреляционной связи между рассматриваемыми величинами (рис. 1) на разделе суши (красные) и моря (синие). Линией раздела аномалий «облако» точек континента и моря служат аномалии силы тяжести примерно с нулевыми значениями. Для территории Республика Удмуртия и Пермского края «облако» занимает интервал по оси абсцисс от 5 до 15 мГал.

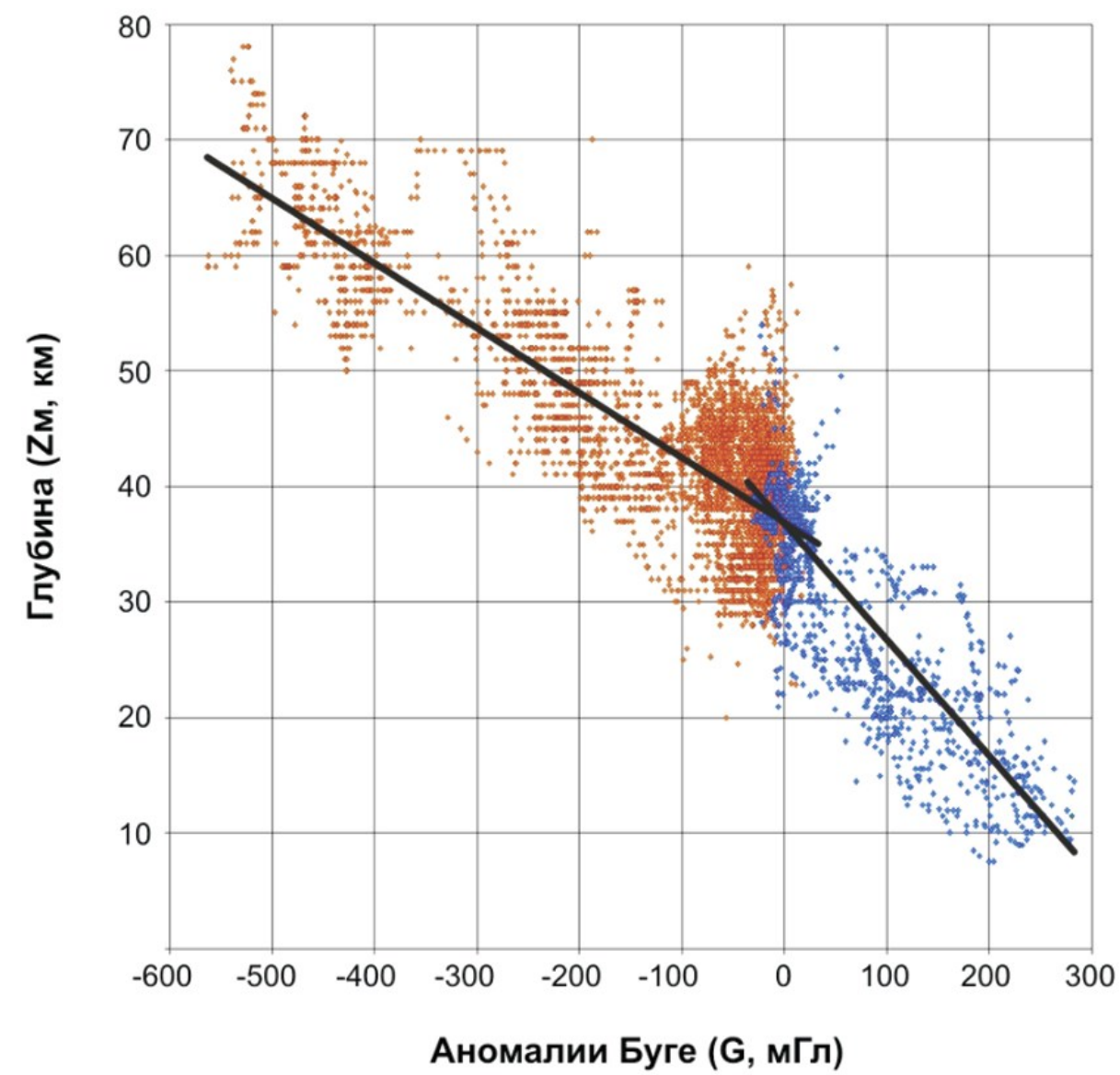

Рис. 1. Поле корреляции глубины Мохо и аномалии силы тяжести в редукции Буге (Кашубин и др. 2011)

\section{Глобальные модели границы Мохо}

По данным сейсморазведочным методам с привлечением имеющейся информации по гравиметрии и других источников построены примерно десять известных карт-схем глобальных моделей границы Мохо [1-12].

На рис. 2 приведена [7] карта поверхности границы Мохо Европейской платформы (Warsaw / Heisinki, September 2007) по сейсмическим данным (фрагмент) и на рис. 3 целенаправленный горизонтальный срез информационного гравиметрического куба, полученного в системе ВЕКТОР. По своей сути срез является аналогом, который соответствует закономерности изменения глубин рельефа Мохо.

Фрагмент глобальной карты (рис. 2) также отображает приподнятую куполовидную область границы Мохо, достаточно уверенно выделяемую по отметкам «40 км». В центральной части глубина уменьшается до отметок менее чем 35 км. Купол характеризуется субпараллельными линеаментами северо-западного простирания. 


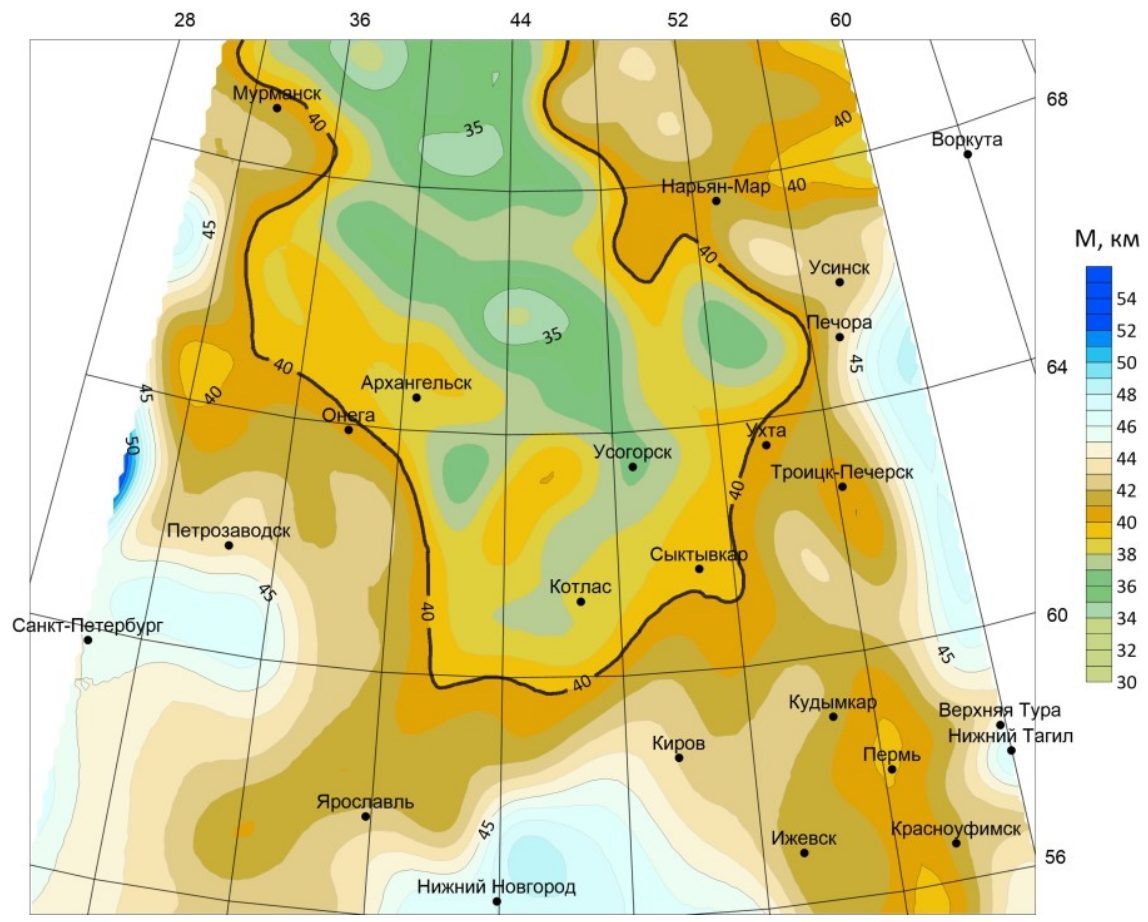

Рис. 2. Глобальная структурная карта (фрагмент) глубины Мохо

Горизонтальный гравиметрический срез (рис. 3) в системе «ВЕКТОР» также позволяет выделить купол с прослеживанием основных тектонических особенностей поверхности Мохо (рис. 2).

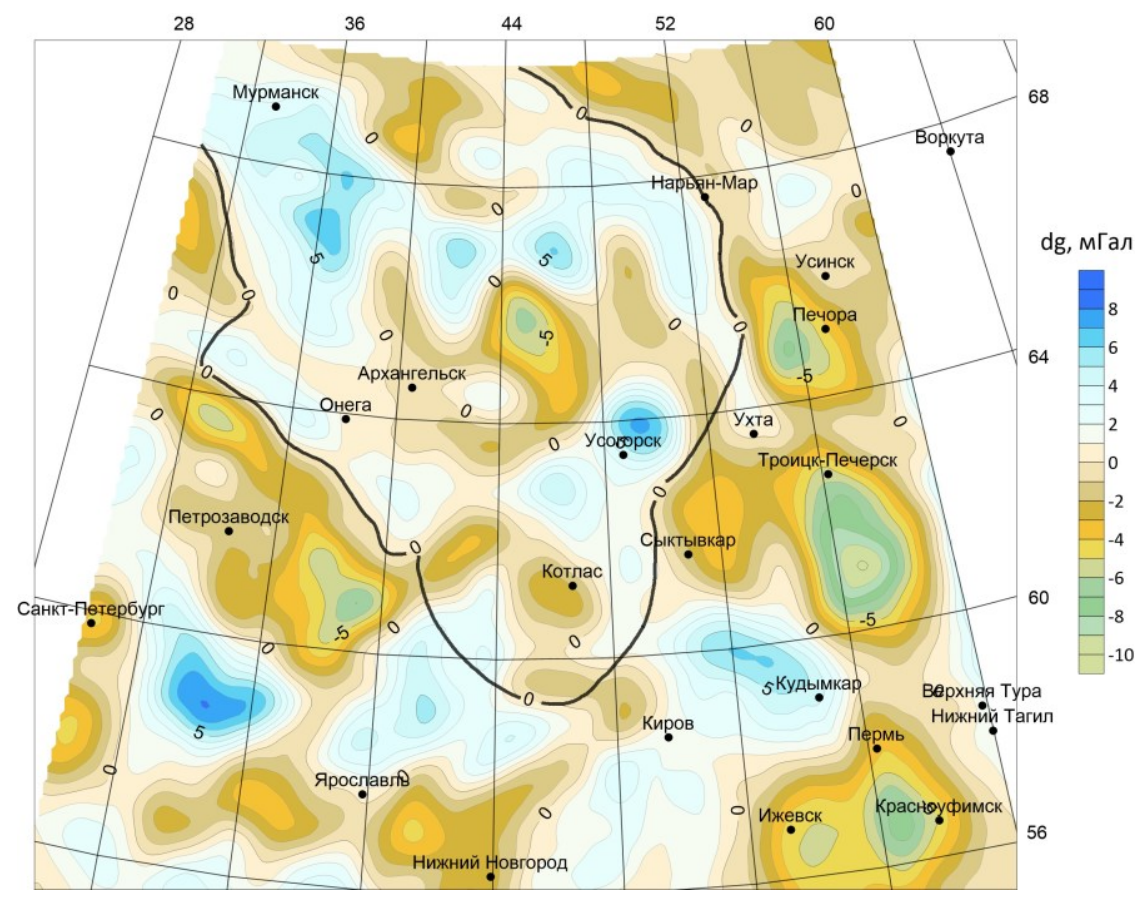

Рис. 3. Горизонтальный срез диаграммы $3 \mathrm{D}$ в системе BЕКТОР на уровне поверхности Мохо Европейской платформы по гравиметрическим данным (фрагмент)

На рис. 4 дана глобальная модель сейсмо-гравитационной карты глубин поверхности Мохо (Тибет) на основе комбинации модели CRUST2.0 и GOCE data. На рис. 5 изображён высокогорный рельеф Тибета. 


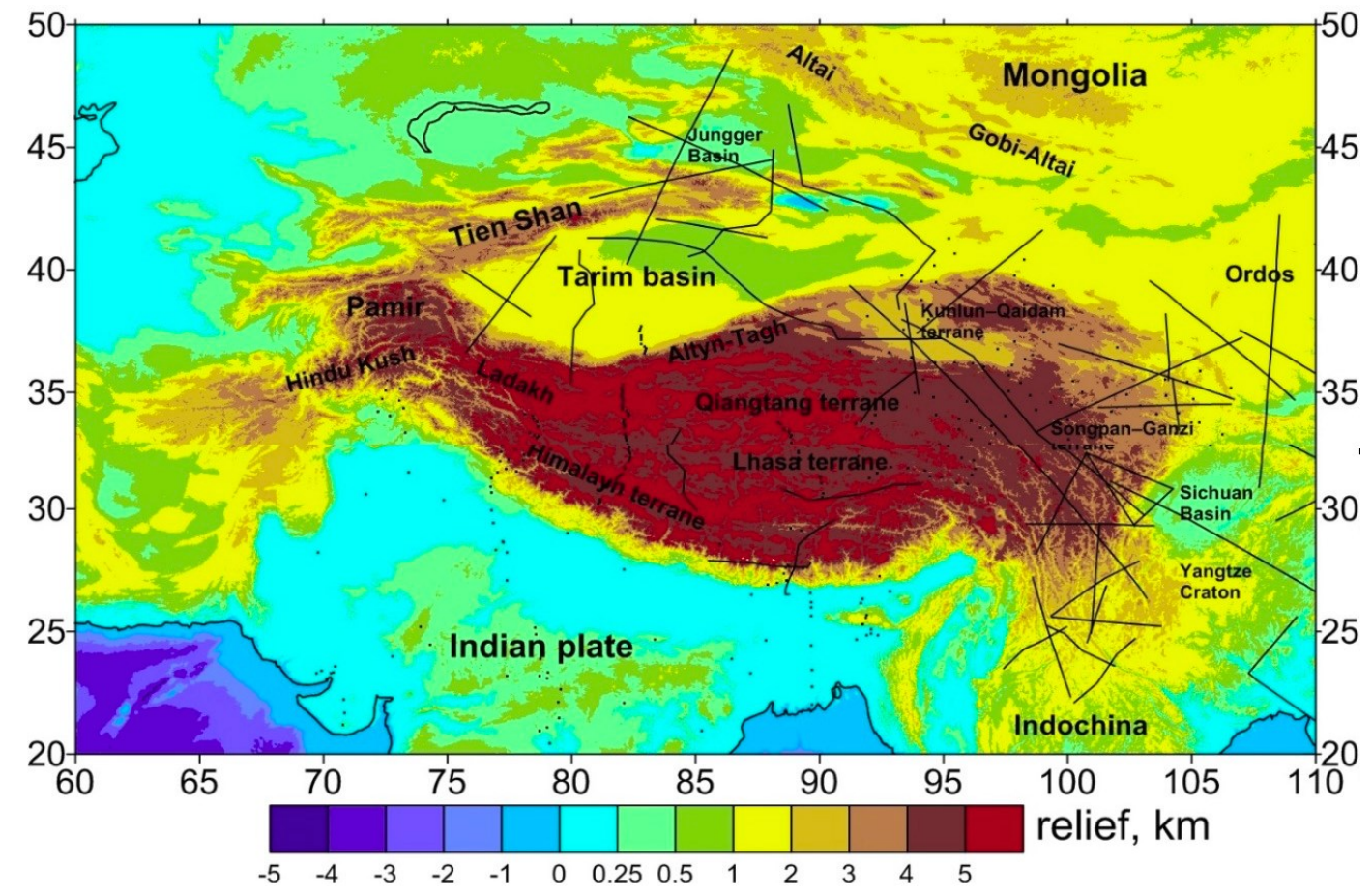

Рис. 4. Карта горного рельефа местности. ТИБЕТ

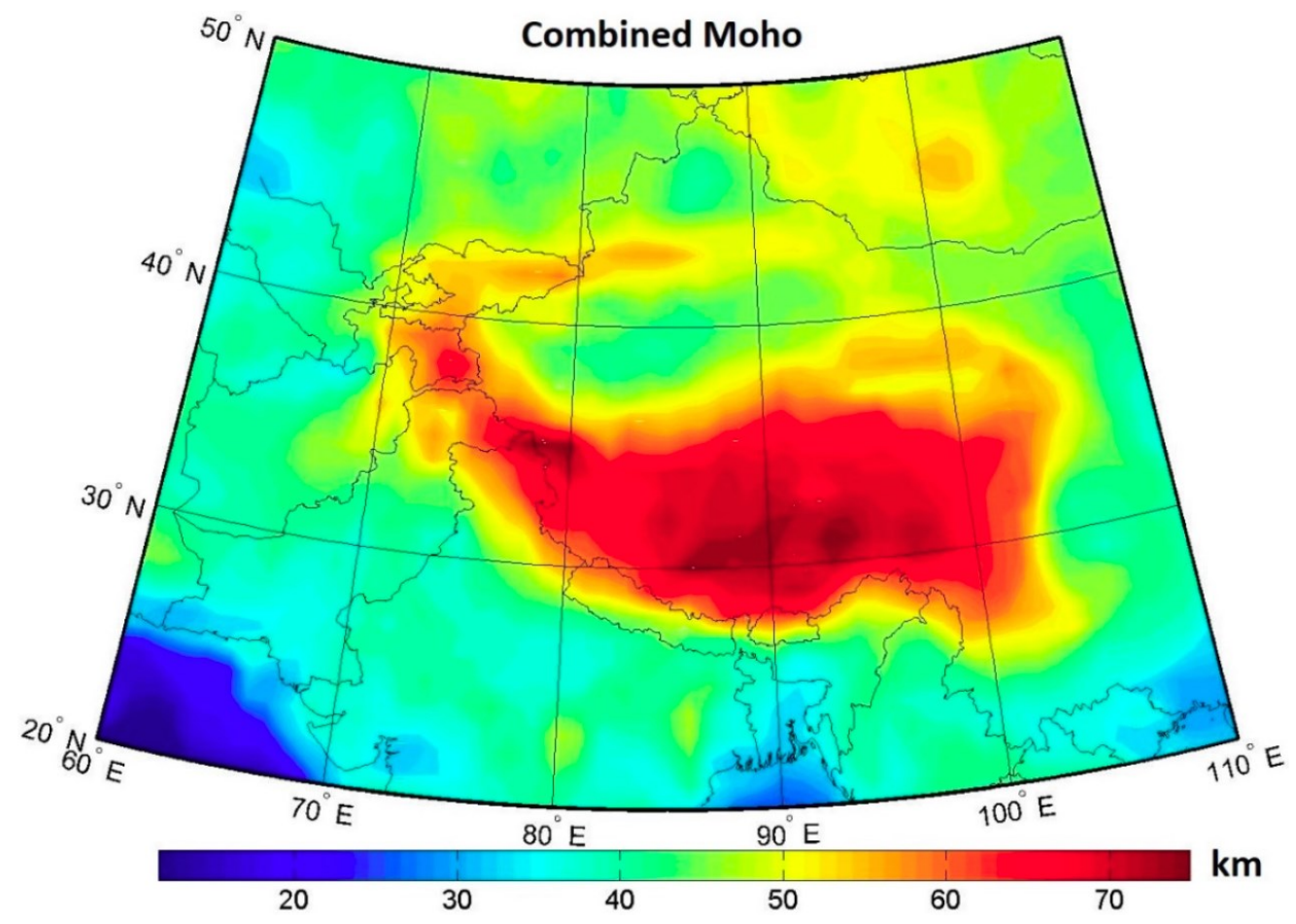

Рис. 5. Глобальная модель карты Мохо на основе сейсмической модели CRUST2.0 и данных гравиметрии GOCE data. ТИБЕТ

Глобальная модель планетной карты границы Мохо - GlobalMoho from the combination of the CRUST2.0 model and GOCE data - составлена итальянскими учёными на основе комбинации сейсмической модели $\boldsymbol{C R U S T 2 . 0}$ и результатов обработки гравиметрических измерений $\boldsymbol{G O C E} \boldsymbol{d a t a}$. В связи с этим использован аппарат GOCE (Gravity field and steady-state Ocean Circulation Explorer - спутник для исследования гравитационного поля и постоянных океанических течений). 


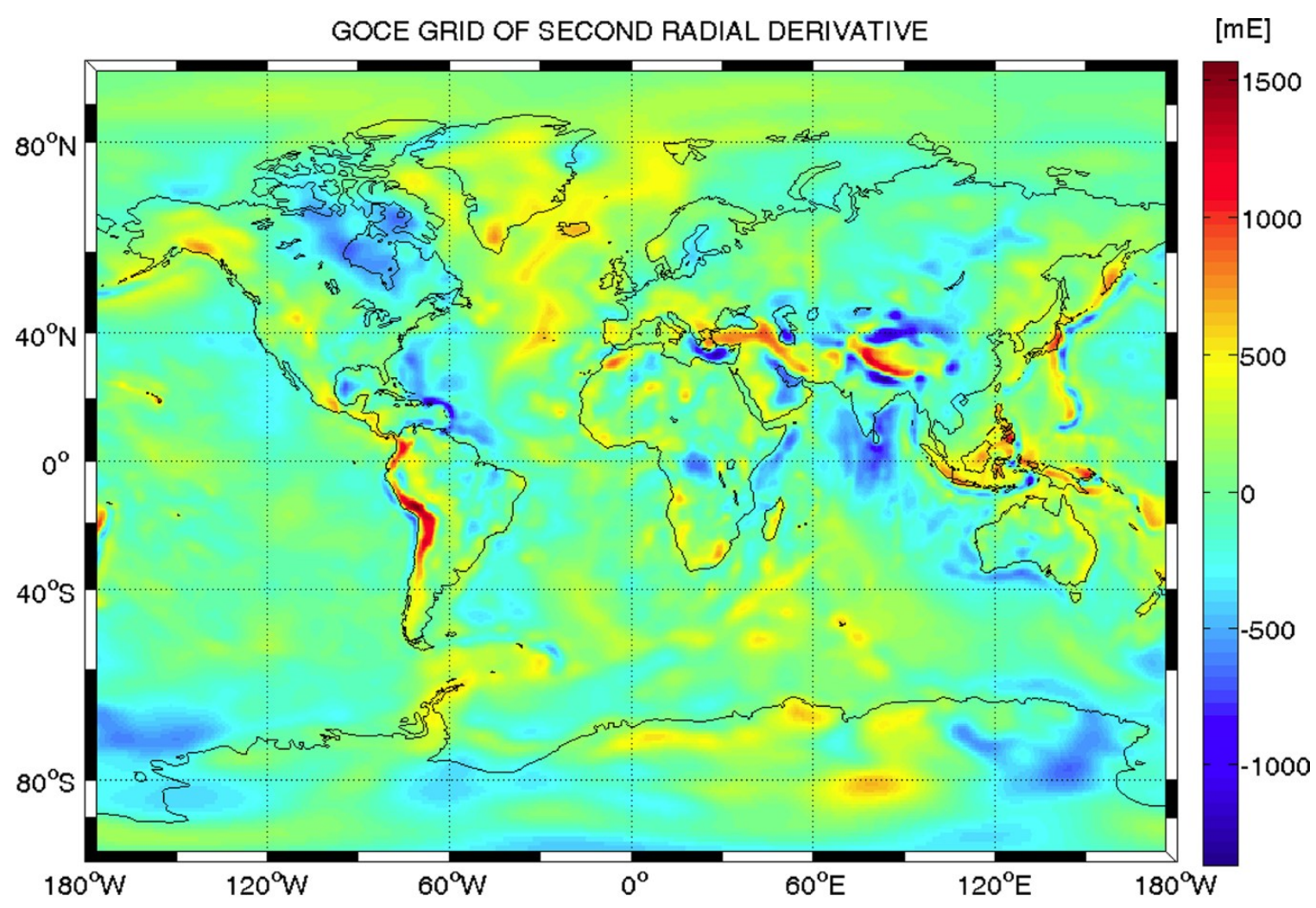

Рис. 6. Карта второй радиальной производной гравитационного потенциала

\section{БИБЛИОГРАФИЧЕСКИЙ СПИСОК}

1. Кашубин С.Н., Петров О.В., Андросов Е.А., Морозов А.Ф., Каминский В.Д., Поселов В.А. Карта мощности земной коры Циркумполярной Арктики // Региональная геология и металлогения. - 2011. - № 46. - С. 5-13.

2. Маловичко А.К. Методы аналитического продолжения аномалий силы тяжести и их приложения к задачам гравиразведки. - М.: Гостоптехиздат, 1956. - 160 с.: ил.

3. Чадаев М.С., Костицын В.И., Гершанок В.А., Ибламинов Р.Г., Тарантин М.В., Простолупов Г.В. Геолого-геофизические методы изучения земной коры: Монография / под общ. ред. М.С. Чадаева; ПГНИУ, ГИ УрО РАН. - Пермь, 2019. - 148 с.

4. Чадаев М.С., Костицын В.И., Ибламинов Р.Г., Гершанок В.А., Простолупов Г.В., Тарантин М.В. Тектоника земной коры территории Пермского края по данным гравиметрии и магнитометрии // Геофизика. - 2016. - № 5. - С. 47-52.

5. Шаров Н.В. Литосфера Северной Европы по сейсмическим данным. - Петрозаводск: Карельский науч. центр РАН, 2017. - 168 с.: ил.

6. Reguzzoni M., Sampietro D., Sanso F. Global Moxo from the combinanation of the CRUST2.0 model and GOCE data // Geophysical journal International. - 2013. - V. 195, № 1. - P. 222-237. https://doi.org/10.1093/gji/ggt247.

7. Grad, M., Tiira, T. The Moho depth map of the European Plate // Geophysical journal international. - 2009. - V. 176, № 1. - C. 279-292. https://doi: 10.1111/j.1365-246X.2008.03919.x.

8. Sioberg L.E., Bagherbandi M. A method of estimating the Moho density contrast with a tentative application of EGM08 and CRUST2.0 // Acta Geophysica. - 2011. - V. 59, № 3. - P. 502-525.

9. Baranov A., Bagherbandi M., Tenzer R. Combined Gravimetric-Seismic Moho Model of Tibet // Geosciences (Switzerland). - 2018. - V. 8, 12. - P. 461. https://doi.org/10.3390/geosciences8120461.

10. Sneeuw N., van Gelderen M. The polar gap // Geodetic Boundary Value Problems in View of the One Centimeter Geoid. - Springer Link, 1997. - V. 65. - P. 559-568. - (Lecture Notes in Earth Sciences).

11. Soller D.R., Ray R.D., Brown R.D. A new global crustal thickness map // Tectonics. - 1982. - V. 1. - P. 125-149.

12. Strang van Hees G.L. Some elementary relations between mass distributions inside the Earth and the geoid and gravity field // Journal of Geodynamics. - 2000. - V. 29, № 1-2. - P. 111-123. https://doi.org/10.1016/S0264-3707(99)00007-1. 